\title{
Unilateral Double Axillary and Double Brachial Arteries. Embryological Basis and Clinical Implications
}

\author{
Arterias Axilar y Braquial Dobles Unilaterales. Bases Embriológicas e Implicaciones Clínicas
}

\author{
Jayakumari, S.; Gayatri Rath \& Jyoti Arora
}

JAYAKUMARI, S.; RATH, G. \& ARORA, J. Unilateral double axillary and double brachial arteries. Embryological basis and clinical implications. Int. J. Morphol., 24(3):463-468, 2006.

SUMMARY: This report presents double axillary and double brachial arteries on the right side of an adult male cadaver. In this case, the right axillary artery bifurcated into axillary artery I and axillary artery II posterior to the pectoralis minor muscle. Both the axillary arteries with their branches traversed upto lower border of teres major muscle and continued further as seperate entities into the cubital fossa as brachial artery I and brachial artery II respectively. The axillary artery I which continued as brachial artery I was superficial and tortuous in its course, while the axillary artery II was slender and deeply situated. The thoraco-acromial, lateral thoracic and subscapular arteries took origin from axillary artery I. The superior thoracic artery was seen arising from the thoraco-acromial artery. The anterior and posterior circumflex humeral arteries arose from axillary artery II.The profunda brachii artery was given off by the brachial artery II, while at the level of intercondylar line, the ulnar artery was given off by brachial artery I. In the cubital fossa, the brachial artery it divided into radial and common interosseous artery, while the brachial artery II ended by anastomosis with brachial artery I. The ulnar, radial and common interosseous arteries continued as separate entities and exhibited a normal course and distribution in the forearm. The hypothesis for the embryological basis of persistence of double axillary and double brachical arteries may be useful for experimental embryology. The knowledge of such multiple arterial variations as in the present case is of immense significance during Doppler scanning of blood vessels for clinical diagnosis and surgical management of diseases of superior extremity.

KEY WORDS: Axillary artery; Brachial artery; Anatomical variation.

\section{INTRODUCTION}

The axillary artery extends from outer border of first rib to the inferior border of teres major muscle, where it continues as brachial artery. The course of the axillary artery is divided into three parts by the pectoralis minor muscle (Williams et al., 1995; Sinnatamby 2001). Maraspin (1971) has reported the bifurcation of the second part of the axillary artery into superficial brachial and deep brachiothoracic branches. Jurjus et al. (1999) observed bifurcation of the second part of the axillary artery into two medium sized arteries. The most frequent anatomic variations of the axillary artery are the persistent superficial brachial artery, high division of the brachial artery, radial artery and ulnar artery (McCormack et al., 1953; Jurjus et al., 1986; Compta 1991; Baeza et al.,1995). Extensive studies on the principal arteries of the upper limb have been carried out. (Adachi, 1928; Huelke, 1959; Keen, 1961; Durgun et al., 2002). Duplex ultrasonography for detecting peripheral vascular injures and Doppler pressure studies for examination of arterial pressure index are commonly used diagnostic procedures (Johansen et al., 1991; Taub et al., 1999) in vascular surgery.To the best of our knowledge, such a rare combination of double axillary and double brachial arteries with variant branching pattern has not been reported earlier. A detailed knowledge of variations of branching pattern of vessels is essential for providing accurate diagnosis and repair of blood vessels in surgical emergencies.

\section{CASE REPORT}

A case of double axillary and double brachial arteries was observed on the right side of an adult Indian male cadaver during routine educational dissection. The first part of axillary artery (Fig 1.1) extended from the outer border of the first rib to upper border of pectoralis minor muscle. It was 2.3 $\mathrm{cm}$ in length and no branches took origin from this part.It then traversed behind the pectoralis minor muscle and 1.2 
$\mathrm{cm}$ from its upper border bifurcated into axillary artery I (Fig. 1.2) and axillary artery II (Fig. 1.3).

The axillary artery I was superficial, tortuous and coursed medial to medial root of median nerve (Fig. 3). At the point of origin of axillary artery I, thoraco-acromial artery was given off (Fig. 1.4). The thoraco - acromial artery was only $0.3 \mathrm{~cm}$ in length and gave five branches - superior thoracic, clavicular, deltoid, pectoral and acromial. These branches displayed normal course and distribution. The lateral thoracic artery (Fig.1. 5) took origin $1.5 \mathrm{~cm}$ distal to the origin of thoraco - acromial artery.The larger subscapular artery was seen arising from axillary artery I, (Fig.1.6) close to the superior border of subscapularis muscle and coursed on the costal surface of this muscle.Thereafter, the axillary artery I continued as brachial artery I, distal to inferior border

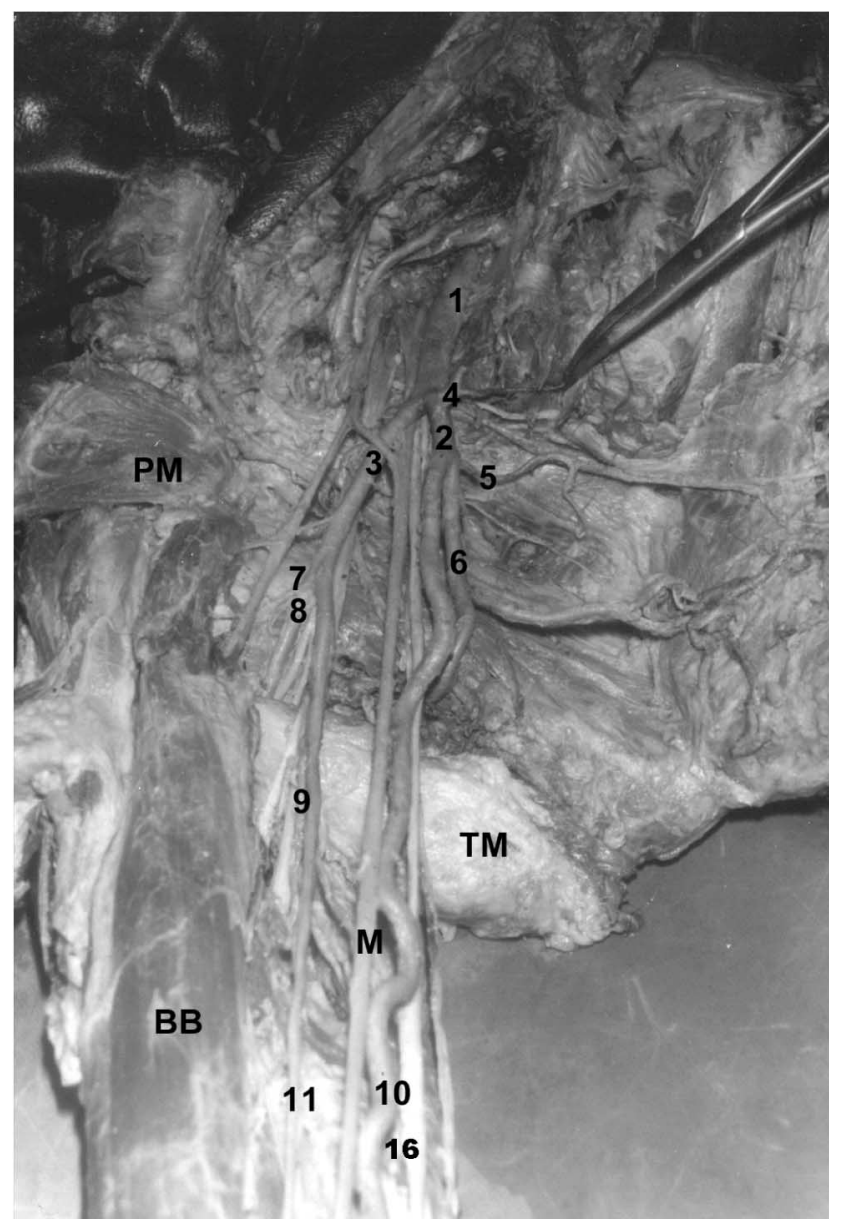

Fig. 1. Photograph showing bifurcation of the right axillary artery and their branching pattern in relation to pectoralis minor muscle (PM), teres major muscle (TM); biceps brachii muscle (BB) and median nerve (M). 1. Axillary artery; 2 . Axillary artery I; 3 . Axillary artery II; 4. Thoraco acromial artery; 5. Lateral thoracic artery; 6. Subscapular artery; 7. Anterior circumflex humeral artery; 8. Posterior circumflex humeral artery; 9.Profunda brachii artery; 10. Brachial artery I; 11. Brachial artery II; 16. Ulnar nerve. of teres major muscle. The brachial artery I coursed downwards along the medial side of the median nerve and was also superficial and tortuous. Proximal to the intercondylar line it gave off the ulnar artery (Fig. 2.12) and then crossed the median nerve under cover of bicipital aponeurosis. The brachial artery I coursed further for a distance of $1.7 \mathrm{~cm}$ and then divided into radial and common interosseous arteries (Fig. 3) at the level of neck of radius.

The axillary artery II was slender, and coursed in a deeper plane than axillary artery I. It was related superfically to ' $\mathrm{V}$ 'shaped union of medial and lateral roots of median nerve. It gave off the anterior and posterior circumflex humeral arteries at the inferior border of subscapularis (Fig. $1.7,8)$ and these branches followed their normal course in relation to surgical neck of humerus and quadrangular space of axilla. At the lower border of teres major muscle, the axillary artery II continued as a brachial artery II. The latter coursed deep to biceps brachii muscle and lateral to the

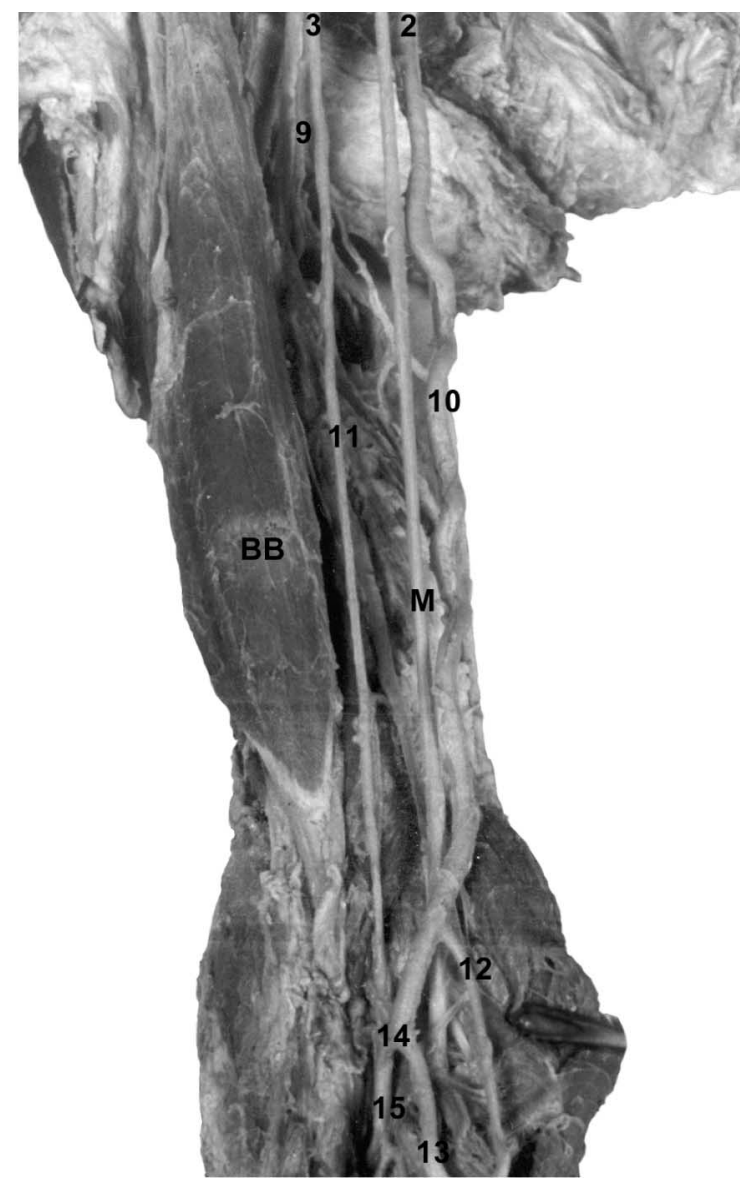

Fig. 2. Photograph showing double axillary and double brachial arteries in the right arm. 2. Axillary artery I; 3. Axillary artery II; 9. Profunda brachii artery; 10 . Brachial artery I; 11 . Brachial artery II; 12. Ulnar artery; 13. Radial artery; 14. Anastomosis between the brachial arteries; 15.Common interosseous artery. 


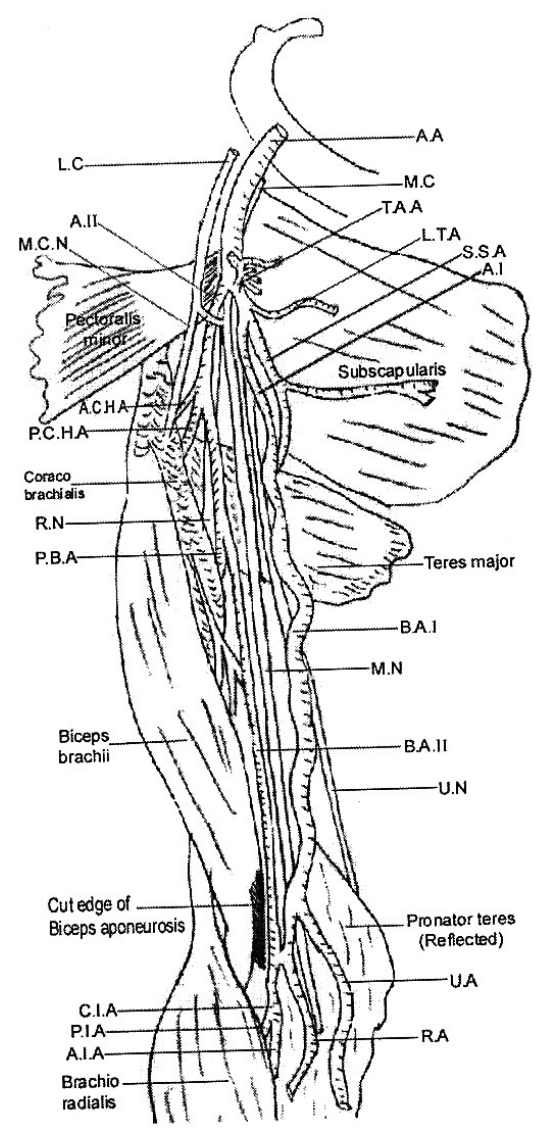

Fig. 3. Diagrammatic represantation of the arteries of the axilla, arm and cubital fossa. AA- $\mathrm{I}^{\text {st }}$ part of axillary artery; AI-axillary artery I; AII - axillary artery II; TAA - thoraco-acromial artery; LTA - lateral thoracic artery; SSA - subscapular artery; ACHAanterior circumflex humeral artery; PCHA- posterior circumflex humeral artery; PBA-profunda brachii artery; BAI - brachial artery I; BAII - brachial artery II; LC - lateral cord; MC - medial cord; $\mathrm{MN}$ - median nerve; UN - ulnar nerve; MCN- musculocutaneous nerve; RN - radial nerve; UA - ulnar artery; RA - radial artery; CIA - common interosseous artery; PIA - posterior interosseous artery; AIA - anterior interosseous artery.

median nerve.The profunda brachii, superior and inferior ulnar collateral arteries were normal in their origin and course. The brachial artery II continued further in the cubital fossa and terminated by anastomosing with brachial artery I where the latter divided into radial and common interosseous arteries. This formed an important site which marked the termination of both brachial arteries and commencement of radial and common interosseous arteries at level of neck of radius (Fig. 3).

The ulnar, radial and common interosseous arteries followed the normal course in the forearm and hand. On the left side of the same cadaver, the axillary and brachial arteries were normal in course and distribution.

\section{DISCUSSION}

The distribution and course of the arteries of superior extremity of human beings are subject to multiple variations at different levels, as reported in earlier studies(Adachi, 1928; Baeza, 1995). To facilitate discussion, the present study has been highlighted under the following headings:

Double axillary arteries. Yotova \& Novakov (2004) observed division of the axillary artery into regular and variant branches at the upper border of pectoralis minor muscle. The regular branch continued as brachial artery and then divided into radial and ulnar branches in cubital fossa.The variant branch continued as profunda brachii artery. Maraspin (1971) observed the bifurcation of second part of the axillary artery into superficial brachial and deep brachiothoracic arteries. Compta (1991) noticed the division of third part of axillary artery into an anterior branch, which constituted the high origin of radial artery and a posterior branch which was the proper brachial artery. De Garis and Swartley (1928) reported, the bifurcation of second part of the axillary artery into radial and ulnar arteries and in some cases into brachial and subscapular artery. Cavdar (2000) observed the division of third part of axillary artery into the lateral deep brachial artery and medial superfical brachial branch. In the present case, although the first part of axillary artery was normal in its course and relations, interestingly, it gave no branches at this level. However, the second part divided into two branches, axillary artery I and axillary II deep to pectoralis minor. Both these arteries traversed up to lower border of teres major muscle and continued as brachial artery I and brachial artery II. Significantly, the two arteries exhibited different relations to median nerve and it's roots. The axillary artery I was medial to the median nerve while the axillary artery II was superficially related to the site of union of the medial and lateral roots of median nerve. The ulnar nerve was medial to axillary artery I. This highlights the importance of such a variation not only in arterial dieaseas but also in surgical management, of nerve injuries.

Huelke (1959), observed the variations in origin of superior thoracic artery from thoraco-acromial artery, second part of axillary artery or from the subclavian trunk. Adachi (1928), reported, superior thoracic artery arising from axillary artery in $70 \%$ cases and in $30 \%$ most commonly from the thoraco - acromial artery.

Interestingly, the superior thoracic artery took origin from thoraco- acromial artery which shared a common site of origin with axillary artery I and II. In an extensive dissection of 512 adult human cadavers, De Garis \& Swartley 
(1928) reported a variable percentage in the origin of lateral thoracic artery from thoraco - acromial artery, from the subscapular artery or from second part of axillary artery. In the present case the lateral thoracic artery took origin behind the pectoralis minor from axillary artery I. The origin of anterior and posterior circumflex humeral arteries from the subscapular artery or from the ulnar artery have also been observed (De Garis \& Swartley 1928). The anterior and posterior circumflex humeral arteries in this case took origin from axillary artery II below the pectoralis minor. Keen (1961) noticed that in $15 \%$ of cases the subscapular artery emerged from the second part of axillary artery whereas in $0.6 \%$ of cases it arose from the first part of axillary artery. Trotter et al. (1930) observed, the bifurcation of subscapular artery into anterior and posterior circumflex humeral branches. Poteat (1986) reported the origin of lateral thoracic and posterior circumflex from subscapular artery and the anterior circumflex artery directly from the axillary artery. In the present case the subscapular artery took origin from axillary artery I. Hence, the axillary artery I gave rise to lateral thoracic and subscapular branches and the the axillary artery II gave off anterior and posterior circumflex humeral arteries. Although the branches of axillary artery I \& II in our study corresponded to the branches of second and third part of axillary artery of normal description, their seperate origin from axillary artery I \& axillary artery II were distinctly variant and unique.

Double brachial arteries. Yoshinaga et al. (2003) observed bifurcation of brachial artery into a large superficial branch and a small deep branch at the distal border of teres major muscle. The superficial branch further divided into radial and ulnar arteries in the cubital fossa,while the deep branch mainly supplied the muscles of arm. Kodama (2000) observed the continuation of the superficial brachial artery as radial artery and deep brachial artery as ulnar artery. Baeza et al. (1995) noted duplication of brachial artery and reported that superficial brachial artery ended by anastomosing with the radial artery in the cubital fossa and in few cases, it continued as antibrachial artery. In our study the axillary artery I and II continued as brachial artery I and brachial artery II respectively at the lower margin of teres major muscle. The brachial artery I was superficial, tortuous, dilated and exhibited a normal course. The brachial artery II was slender, situated deep to biceps brachii muscle. The brachial artery II coursed under cover of bicipital aponeurosis and ended by anastomosing with brachial artery I in the cubital fossa.

Keen (1961 ) noticed the origin of profunda brachii artery from terminal part of axillary artery in $26 \%$ of cases and from posterior circumflex humeral or from subscapular artery in $6 \%$ of cases. Keller et al. (1980) reported the origin of the profunda brachial artery from deep brachiothoracic artery at the level of inferior border of pectoralis minor muscle. Jurjus et al. (1986) observed the origin of profunda brachial artery prior to division of brachail artery I \& II. He also recorded the bifurcation of brachial artery I into radial and ulnar arteries in cubital fossa,and further continuation of brachial artery II as common interosseous artery.

Yoshinaga et al. (2003) observed the termination of deep brachial artery as inferior ulnar collateral artery in the middle of the arm. Most studies report the common interosseous artery as a branch of ulnar artery (Williams et al., 1995; Moore et al., 1999). The incidence of origin of common interosseous from radial artery is uncommon.Such an unusual origin of common interosseous from radial artery and the termination of brachial artery II also at this site is seen in our case. Melling et al. (2000) observed the bifurcation of the brachial artery into superficial brachial artery and deep brachial artery. The superficial brachial artery coursed anterior to the bicipital aponeurosis to continue as radial artery while the deep brachial artery was deep to the aponeurosis and continued as ulnar artery. In the present case, brachial artery I gave off ulnar artery $1.2 \mathrm{~cm}$ proximal to intercondylar line and then continued further to meet brachial artery II in the cubital fossa. Thereafter, the brachial artery I divied into radial artery \& common interosseous artery. Such an anastomotic site formed by four important arteries in the cubital fossa i.e; brachial artery I, its division into radial and common interosseous arteries and also the termination of brachial artery II at this same site is of utmost importance in vascular and orthopedic procedures of arm, elbow joint and forearm.

Embryological basis. The embryological source of these variations may be explained as an abnormal deviation from the normal process of embryonic development of vascular plexus. Persistance of lateral branch of more than one cervical intersegmental artery which becomes enlarged to form a double axis artery (Jurjus et al., 1999). According to Moore $\&$ Persand (2003) the proximal part of the right subclavian artery develops from right fourth aortic arch while the distal part is from right dorsal aorta and right seventh intersegmental artery. We hypothesize that the embryological basis of the present variation on the right side may be due to abnormal division of distal part of the seventh cervical intersegmental artery which countinued to develop into double axial arteries. In the proximal part, the seventh cervical intersegmental artery fused normally with fourth aortic arch artery. Contribution from a persistent segment of dorsal aorta cannot be ruled out.

Clinical relevance. The clinical importance of the described axillary variation is of utmost significance for 
surgeons,cardiologists and vascular specialists. It is specially relevant in cases of arteriovenous fistulae, aneurysms and abcess drainage in region of axilla, arm and cubital fossa. (Taub et al.,1999) In angiographic studies preceeding coronary artery bypass surgery such aberrant anatomy should be timely confirmed to reduce the incidence of iatrogenic injuries. An abnormal superficial tortuous brachial artery as in this case may be mistaken for basilic vein during cannulation (Hazlett,1949; Karlsson et al., 1982). Axillary and brachial artery variations are relevant in shoulder, arm and forearm sugery, in fractures \& dislocations. Awareness of such abnormal axillary vasculature is crucial in use of superficial brachial artery flap in plastic surgery (Iwahira et al., 1996) and protection of axillary artery in breast cancer surgery. Undoubtedly, such variations are important for diagnostic evaluation and surgical management of vascular diseases and injuries.

JAYAKUMARI, S.; RATH, G. \& ARORA, J. Arterias axilar y braquial dobles unilaterales. Bases embriológicas e implicancias clínicas. Int. J. Morphol., 24(3):463-468, 2006.

RESUMEN: Este reporte describe la presencia de las arterias axilar y braquial duplicadas en el lado derecho de un cadáver adulto de sexo masculino. La arteria axilar derecha se bifurcó en arterias axilares I y II, localizadas posteriormente al músculo pectoral menor. Ambas arterias, con sus respectivas ramas atravesaron bajo el músculo redondo mayor y continuaron como arterias braquiales I y II, respectivamente. La arteria axilar I, que se continuó como arteria braquial I, tuvo un trayecto superficial y tortuoso, mientras que la arteria axilar II fue de poco calibre y de localización profunda. Las arterias toracoacromial, torácica lateral y subescapular se originaron de la arteria axilar I. La arteria torácica superior se originó de la arteria toracoacromial. Las arterias circunflejas humerales anterior y posterior se originaron desde la arteria axilar II. La arteria braquial profundase originó de la arteria braquial II, mientras que a nivel de la línea intercondílea, la arteria ulnar se originó de la arteria braquial I. En la fosa cubital, la arteria braquial I se dividió en arterias radial e interósea común, mientras que la arteria braquial II terminó anastomosándose con la arteria braquial I. Las arterias ulnar, radial e interóseas común continuaron como arterias independientes y tuvieron un trayecto y distribución normales en el antebrazo. La persistencia de arterias axilar y braquial dobles tiene una base embriológica, pudiendo ser de interés para la embriología experimental. El conocimiento de estas variaciones arteriales múltiples, como el presente caso, es de importancia fundamental durante la medición de flujo en los vasos sanguíneos a través de Doppler, para el diagnóstico clínico y manejo quirúrgico de enfermedades que afectan al miembro superior.

PALABRAS CLAVE: Arteria axilar; Arteria braquial; Variación anatómica.

\section{REFERENCES}

Adachi, B. Das Arteriensystem der Japaner. Kyoto, Maruzen, 1928. V. 1. pp 215-75.

Cavdar, S.; Zeybek, A. \& Bayramicli, M. Rare variation of the axillary artery. Clin. Anat., 13:66-8, 2000.

Chummy S. Sinnatamy. Last's Anatomy Regional and applied. $10^{\text {th }}$ Ed. New York, Churchill Livingston, 2001. pp 48-55.

Compta, X. G. Origin of the radial artery from the axillary artery and associated hand vascular anomalies. J. Hand Surg. [Am]. 16-A:293-6, 1991.

De Garis, C. F. \& Swartley, W. B. The axillary artery in white and Negro stocks. Am. J. Anat., 41:353-97, 1928.

Durgun, B; Yucel, A. H.; Kizilkanat, E. D. \& Dere, F. Multiple arterial variation of the human upper limb. Surg. Radiol. Anat., 24:125-8, 2002.
Hamilton, W. J. \& Mossman, H. W. Cardiovascular System. In. Human Embryology. 4th Ed. Baltimore, Williams \& Wilkins, 1978. pp. 268-72.

Hazlett. J. W. The superficial ulnar artery with reference to accidental intra-arterial injection. Can. Med. Assoc., 61:289-93, 1949.

Huelke, D. F. Variation in the origins of the branches of the axillary artery. Anat. Rec., 35:33-41, 1959.

Iwahira, Y.; Maruyama, Y. \& Hayashi, A. The superficial brachial flap. Ann. Plast. Surg., 37:48-54, 1996.

Jurjus, A.; Sfeir, R. \& Bezirdjian, R. Unusual variation of the arterial pattern the human upper limb. Anat. Rec., 215:82-3, 1986.

Jurjus, A. R.; Correa-De-Aruaujo, R. \& Bohn, R. C. Bilateral double axillary artery:Embryological basis and clinical implications. Clin. Anat., 12:135-40, 1999. 
Johansen. K.; Lynch, K.; Paun, M. \& Copass, M. K. Noninvasive vascular tests reliably exclude occult arterial trauma in injured extremities. J. Trauma, 31:515-22, 1991.

Karlsson, S. \& Niechajev. I. A. Arterial anatomy of the upper extremity . Acta Radiol. [Diagn] (Stockh), 23:115-21, 1982.

Keen, J. A. A study of the arterial variations in the limbs, with special reference to symmetry of vascular patterns. Am. J. Anat., 108:245-261, 1961.

Keller, F. S.; Rosch, J.; Dotter, C. T. \& Porter, J. M. Proximal origin of radial artery; Potential pitfall in hand anigography. Am. J. Roentgenol., 134:169-70, 1980.

Kodama, K. Arteries of the upper limb. In: Anatomic Variations in Japanese (Salto, T, Akitak, eds). University of Tokyo Press, Tokyo:220-37, 2000.

Maraspin, L. E. A report of an anomalous bifurcation of the right axillary artery in man. Vasc. Surg., 5:133-6, 1971.

McCormack, L. J.; Cauldwell, E. W. \& Anson, B. J. Brachial and antebrachial arterial patterns. A study of 750 extremities. Surg Gynec Obstet., 96:43-54, 1953.

Melling, M.; Wilde, J.; Schnallinger, M.; Karimian- Teherani D.; Behnam, M. \& Firbas W. Rare Variant of the brachial artery: Superficial lateral inferior type VII EAB. Clin. Anat., 13:216-22, 2000.

Moore, K. L. \& Dalley, A. F. Clinically Oriented anatomy. 5th Ed. Lippincott Williams \& Wilkins A Wolters kluwer, 2006. pp 766-93.

Moore, K. L . \& Persand, T. V. N. The Cardio vascular system. In the developing Human, Clinically oriented embryology. $7^{\text {th }}$ Ed. Elsevier, India, 2003. pp. 329-80.

Poteat, W. L. Report of a rare Human variation: Absence of the Radial artery. Anat. Rec., 214:89-95, 1986.

Rodriguez-Baeza, A.; Nebot, J.; Ferreira, B.; Reina, F.; Perez, J.; Saundo, J. R. \& Roig, M. An anatomical study and ontogenetic explanation of 23 cases with variations in the main pattern of the human brachio-antebrachial arteries J. Anat., 187:473-9, 1995.

Rodriguez-Niedenfuhr, M.; Vazquez, T.; Parkin, I. G. \& Sanudo, J. R. Arterial patterns of the human upper limb:update of anatomical variations and embryological development. Eur. J. Anat., 7 suppl., 1:21-8, 2003.
Singer, E . Embryological pattern persisting in the arteries of the arm. Anat Rec., 55:403-09, 1933.

Taub, J.; Giannikis, G.; Shen, H.Y. \& Kim, U. The Brachial artery transection following closed elbow dislocation. $J$. Trauma, 47(1):176-8, 1999.

Trotter, M.; Henderson, J. L.; Gass, H.; Brua, R. S.; Weisman, S.; Agress, H.; Curtis, G. H. \& Westbrook, E. R. The origins of branches of the axillary artery in white and in American Negroes. Anat. Rec., 46:133-7, 1930.

William, P. L.; Bannister, L. H. \& Berry, M. M. et al. In Gray's Anatomy. 38th Ed. New York, Churchill Livingston, 1995. pp 318-320.

Yoshinaga, K.; Ichiro Tannii, I. \& Kodo Kodama, K. Superfical brachial artery crossing over the ulnar and median nerves from posterior to anterior: Embryological significance. Anat. Sci. Int., 78:177-80, 2003.

Yotova, N. \& Novakov, S. Unilateral double axillary artery. Clin Anat., 17:149-51, 2004.

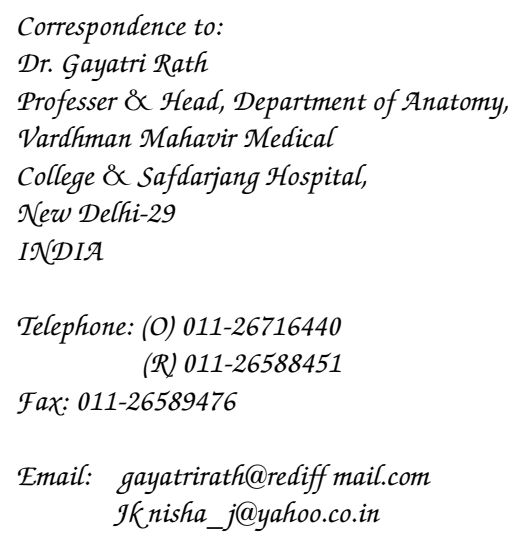

Received: 18-05-2006

Accepted: 22-06-2006 